\title{
Effect of BNNTs/matrix interface tailoring on toughness and fracture morphology of hierarchical $\mathrm{SiC}_{\mathrm{f}} / \mathrm{SiC}$ composites
}

\author{
Guangxiang ZHU ${ }^{a, b, c}$, Qian $\mathrm{FENG}^{d}$, Jinshan $\mathrm{YANG}^{a, b, *}$, Jianbao $\mathrm{HU}^{a, b}$, \\ Hongda WANG ${ }^{a, b}$, Yudong XUE ${ }^{a, b, c}$, Qingliang $\operatorname{SHAN}^{a, b, c}$, Shaoming DONG ${ }^{a, b,{ }^{*}}$ \\ ${ }^{a}$ State Key Laboratory of High Performance Ceramics and Superfine Microstructure, Shanghai \\ Institute of Ceramics, Chinese Academy of Sciences, Shanghai 200050, China \\ ${ }^{b}$ Structural Ceramics and Composites Engineering Research Center, Shanghai Institute of \\ Ceramics, Chinese Academy of Sciences, Shanghai 200050, China \\ ${ }^{c}$ University of Chinese Academy of Sciences, Beijing 100049, China \\ ${ }^{d}$ Analysis and Testing Center, Donghua University, Shanghai 201600, China
}

Received: December 28, 2018; Revised: March 24, 2019; Accepted: May 3, 2019

(C) The Author(s) 2019.

\begin{abstract}
A thin BN interphase is applied on BNNTs surface to tailor the interfacial bonding between BNNTs and $\mathrm{SiC}$ matrix in hierarchical $\mathrm{SiC}_{\mathrm{f}} / \mathrm{SiC}$ composites. The thickness of $\mathrm{BN}$ interphase ranging from 10 to $70 \mathrm{~nm}$ can be optimized by chemical vapor deposition after BNNTs are in situ grown on $\mathrm{SiC}$ fiber surface. Without $\mathrm{BN}$ interphase, the fracture toughness of hierarchical $\mathrm{SiC}_{\mathrm{f}} / \mathrm{SiC}$ composites can be impaired by $13.6 \%$ due to strong interfacial bonding. As long as BN interphase with $30-45 \mathrm{~nm}$ thickness is applied, the interfacial bonding can be optimized and fracture toughness of hierarchical composites can be improved by $27.3 \%$. It implies that tailoring BNNTs/matrix interface by depositing a layer of $\mathrm{BN}$ interphase is in favor of activating energy dissipation mechanisms at nanoscale induced by BNNTs.
\end{abstract}

Keywords: boron nitride nanotubes (BNNTs); interface; nanocomposites; toughness and toughening

\section{Introduction}

Since the first prediction in 1994 and experimentally synthesis in the following year, boron nitride nanotubes (BNNTs) have attracted significant attention from scientists due to their remarkable properties [1]. Due to one-dimensional nanotube structure, BNNTs possess high elastic modulus, high tensile strength, high thermal conductivity, and excellent chemical/thermal

* Corresponding authors.

E-mail: J. Yang, jyang@mail.sic.ac.cn;

S. Dong, smdong@mail.sic.ac.cn stability [1-3]. Therefore, BNNTs reveal a great potential as nanoscale reinforcements in composites, and hierarchical composites can be obtained as long as BNNTs are incorporated into conventional fiber reinforced ceramic matrix composites. Energy dissipation mechanisms triggered by BNNTs at nanoscale, such as debonding, crack deflection, nanotube bridging, sliding, and pull-out, can be applied to improve the toughness in hierarchical composites [4-6]. However, in our previous research, it is found that the strong interface bonding between BNNTs and matrix can limit the toughening effect and the pull-out of BNNTs is very short in $\mathrm{SiC}_{\mathrm{f}} / \mathrm{SiC}$ hierarchical composites [6]. 
A proper interfacial bonding is the key factor to obtain excellent mechanical properties and energy dissipation mechanisms for a composite system, which can lead to reinforcement pull-out for better toughness $[5,7]$. For a brittle matrix like ceramic, it demands the interface weak enough to allow debonding, sliding, and pull-out of nanotubes. In this case, energy dissipation, as well as consequently toughening in matrix, can be aroused [5,7]. Hence, BNNTs/matrix interface is expected to be tailored and in-depth investigated.

In the study, a BN interphase is deposited on BNNT surface by chemical vapor deposition (CVD) to optimize the BNNTs/matrix interfacial bonding. The interphase, which is defined as a thin-layer material with low shear strength, is usually used in micro-scale fiber reinforced composites to control the fiber/matrix interfacial bonding $[8,9]$. Effect of BNNTs/matrix interface tailoring on the fracture toughness and morphology of hierarchical composites is emphatically investigated. Toughening mechanisms of BNNTs/matrix interface tailoring are also discussed based on the investigation.

\section{Experimental procedures}

BN-coated BNNTs reinforced hierarchical $\mathrm{SiC}_{\mathrm{f}} / \mathrm{SiC}$ composites were fabricated by two steps: firstly in situ growing BNNTs on $\mathrm{SiC}$ fiber surface, which can be found in detail in our previous study [10], and subsequently matrix densification via polymer impregnation/pyrolysis (PIP) and chemical vapor infiltration (CVI) method. $(\mathrm{PyC} / \mathrm{SiC})_{n}(n=3)$ multilayer interphase was deposited on $\mathrm{SiC}$ fiber cloths before the in situ growth of BNNTs. In order to tailor BNNTs/matrix interfacial bonding, a thin layer of BN interphase was deposited on the BNNT surface before matrix densification. The interphase deposition was conducted for 10,20 , and $40 \mathrm{~min}$ at $900{ }^{\circ} \mathrm{C}$ using $\mathrm{BCl}_{3}(7.5 \mathrm{sccm})$ and $\mathrm{NH}_{3}(15 \mathrm{sccm})$ as the source gas under a pressure of $0.5 \mathrm{kPa}$. To get thicker interphase and understand the interphase mechanism better, we skipped over $30 \mathrm{~min}$ deposition time and carried out the 40 min deposition instead. Then SiC fiber cloths with BN-coated BNNTs were stacked and compressed together to control the volume fraction of $\mathrm{SiC}$ fiber around $40 \%$. PIP method was carried out for four cycles to introduce $\mathrm{SiC}$ matrix into fiber bundles. Polycarbosilane (PCS) was used as ceramic precursor and pyrolyzed at $900{ }^{\circ} \mathrm{C}$ in $\mathrm{Ar}$ atmosphere. Then CVI method was employed to conduct further $\mathrm{SiC}$ matrix densification. The CVI process was conducted for several cycles at $1000{ }^{\circ} \mathrm{C}$ using methyltrichlorosilane (MTS, $\mathrm{CH}_{3} \mathrm{SiCl}_{3}$ ) and $\mathrm{H}_{2}$ as the source gas. The deposition process of $\mathrm{SiC}$ interphase was as the same as the CVI process of $\mathrm{SiC}$ matrix. The PyC interphase was deposited at $1000{ }^{\circ} \mathrm{C}$ using $\mathrm{C}_{2} \mathrm{H}_{2}$ $(50 \mathrm{sccm})$ as the source gas under a pressure of $4 \mathrm{kPa}$. For comparison, two other composites, including virgin $\mathrm{SiC}_{\mathrm{f}} / \mathrm{SiC}$ composites and hierarchical $\mathrm{SiC}_{\mathrm{f}} / \mathrm{SiC}$ composites with as-grown BNNTs, were also fabricated via the same process as described above.

The bulk density and open porosity of composites were determined via Archimedes method. Three-point bending test was conducted on an Instron-5566 universal testing machine to measure the flexural strength of composites. The fracture toughness of composites was evaluated using single edge notched beam (SENB) method. The morphology and microstructure of as-grown and BN-coated BNNTs were investigated via a Hitachi SU8220 field-emission scanning electron microscope (SEM) and JEM-2100F field emission transmission electron microscope (TEM). Electron energy loss spectroscopy (EELS) attached to TEM and X-ray energy dispersive spectroscopy (EDS) attached to SEM were used to characterize chemical composition of BN interphase on BNNT surface. The fracture morphology of composites was examined via SEM to figure out the effect of BNNTs/matrix interface tailoring. Single fiber push-out test was also performed using a nanoindenter to evaluate the interfacial shear strength (IFSS) between fiber and matrix. The specimens with about $200 \mu \mathrm{m}$ thickness were polished and then placed on a graphite plate with a groove of 2 $\mathrm{mm}$ in width. Fibers in the specimens above the groove were selected and loaded by diamond indenter with spherical tip (Agilent Technologies, $5 \mu \mathrm{m}$ Radius $60^{\circ}$ Diamond Conical) using optic microscopy. For each specimen, ten fibers were selected for IFSS test. The IFSS value can be calculated via Eq. (1) [11]:

$$
\tau=\frac{p}{\pi D h}
$$

where $p, D$, and $h$ are the debonding load or push-out load, diameter of the fiber, and the thickness of the specimen, respectively.

\section{Results}

BNNTs are in situ grown on the surface of SiC fibers 
and a layer of $\mathrm{BN}$ interphase is then deposited on the nanotube surface. The morphology of as-grown and BN-coated BNNTs is exhibited in Fig. 1. From the inset in Fig. 1(a), it is demonstrated that BNNTs are in situ grown on the surfaces of $\mathrm{SiC}$ fibers. It also can be found that as-grown BNNTs have a very smooth surface with the diameter of 30-120 nm, as shown in Fig. 1(a). Moreover, they possess an apparent morphology of the bubble-chain tube walls. It can be attributed to the stress-induced sequential growth mechanism [10]. Figure 1(b) reveals the typical morphology of BN-coated BNNTs with 20 min deposition time. After the deposition of BN interphase, the surface of BNNTs becomes rough and the morphology of the bubblechain tube walls cannot be observed from SEM pictures.

TEM images in Fig. 2 clearly display the microstructure of BN-coated BNNTs. From Figs. 2(a)-2(c), it can be noticed that the nanotube is besieged by $\mathrm{BN}$ interphase utterly and uniformly. By the way, BNNTs have a multi-walled and bamboo-like structure, which is in line with our previous study $[6,10]$. According to TEM observation, the thickness of BN interphase is estimated about $10-20,30-45$, and $45-70 \mathrm{~nm}$ corresponding to different deposition time from 10,20 , to $40 \mathrm{~min}$. The thickness of $\mathrm{BN}$ interphase can also be narrowed to $15-20,40-45$, and $55-60 \mathrm{~nm}$ for 10,20 , to 40 min deposition time using the small zone of TEM picture showing in Figs. 2(a)-2(c). High-resolution TEM image in Fig. 2(d) shows that the BN interphase exhibits a turbostratic structure, which can also be confirmed by the SAED pattern in the inset [12].

In addition, EELS spectrum taken from the interphase, as displayed in Fig. 2(e), presents two distinct absorption peaks of $\mathrm{B}$ and $\mathrm{N}$, demonstrating that the interphase is BN.

Physical and mechanical properties of the composites are given in Table 1. It is well known that the main aim of adding BNNTs into ceramic is to increase the fracture toughness [4], so toughening effect of BNNTs is the primary focus and apparent distinctions in toughness can be found in this research. When BNNTs are introduced into $\mathrm{SiC}_{\mathrm{f}} / \mathrm{SiC}$ composites, the fracture toughness of hierarchical composites is impaired by $13.6 \%$. As long as BN is coated on BNNTs with the deposition time ranging from 10,20 , to $40 \mathrm{~min}$, the fracture toughness is improved by $18.2 \%, 27.3 \%$, and $10.9 \%$, respectively. It implies that a layer of $\mathrm{BN}$ interphase yields a positive effect on tailoring BNNTs/ matrix interface and the fracture toughness of the macroscopic composites.

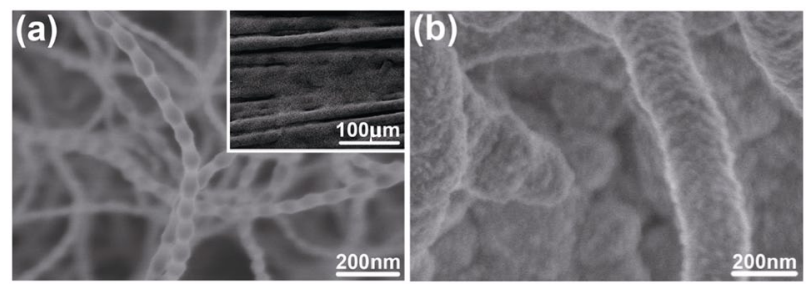

Fig. 1 Typical SEM images of as-grown and BN-coated BNNTs: (a) as-grown BNNTs and (b) BN-coated BNNTs with deposition time of $20 \mathrm{~min}$.
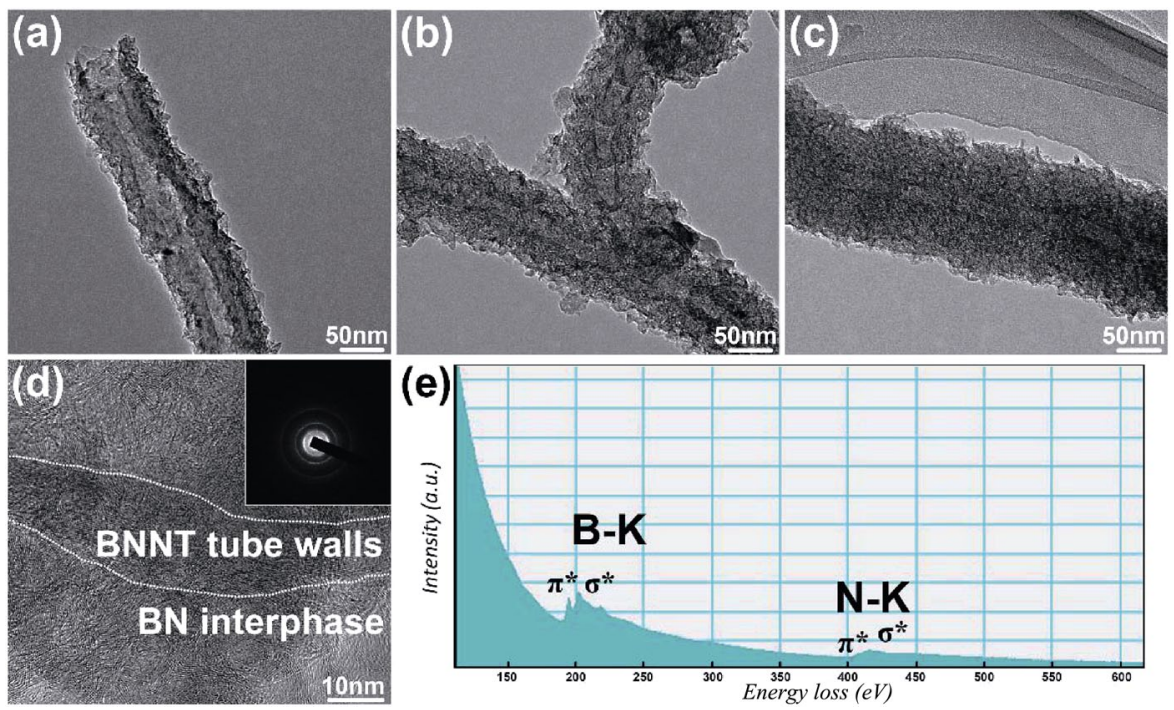

Fig. 2 Representative TEM images of BN-coated BNNTs with deposition time of (a) $10 \mathrm{~min}$, (b) 20 min, and (c) 40 min. The thickness of BN interphase increases as the deposition time prolongs. (d) High-resolution TEM image of BN interphase deposited on the nanotube surface. The inset shows selected area electron diffraction (SADE) pattern of the interphase. (e) EELS spectrum taken from the interphase. 
Table 1 Properties of virgin $\mathrm{SiC}_{\mathrm{f}} / \mathrm{SiC}$ composites, as-grown, and $\mathrm{BN}$-coated $\mathrm{BNNTs}$ reinforced $\mathrm{SiC}_{\mathrm{f}} / \mathrm{SiC}$ hierarchical composites

\begin{tabular}{|c|c|c|c|c|c|c|}
\hline Composite $^{*}$ & $\begin{array}{l}\text { BNNTs content } \\
(\mathrm{wt} \%)\end{array}$ & $\begin{array}{l}\text { Density } \\
\left(\mathrm{g} \cdot \mathrm{cm}^{-3}\right)\end{array}$ & $\begin{array}{c}\text { Open porosity } \\
(\%)\end{array}$ & $\begin{array}{l}\text { Flexural strength } \\
\qquad(\mathrm{MPa})\end{array}$ & $\begin{array}{l}\text { Fracture toughness } \\
\qquad\left(\mathrm{MPa} \cdot \mathrm{m}^{1 / 2}\right)\end{array}$ & $\begin{array}{l}\text { Interfacial shear } \\
\text { strength }(\mathrm{MPa})\end{array}$ \\
\hline $\mathrm{SiC}_{\mathrm{f}} / \mathrm{SiC}$ & 0 & $2.47 \pm 0.03$ & $9.87 \pm 1.1$ & $296.8 \pm 17.6$ & $11 \pm 0.4$ & $59.4 \pm 12.0$ \\
\hline $\mathrm{SiC}_{\mathrm{f}} / \mathrm{BNNTs}-\mathrm{SiC}$ & 1.0 & $2.51 \pm 0.05$ & $6.86 \pm 1.6$ & $306.7 \pm 23.5$ & $9.5 \pm 1.5$ & $119.6 \pm 11.4$ \\
\hline $\mathrm{SiC}_{\mathrm{f}} / \mathrm{BNNTs} / \mathrm{BN}(10)-\mathrm{SiC}$ & 1.0 & $2.49 \pm 0.03$ & $9.15 \pm 1.5$ & $342.5 \pm 11.9$ & $13.0 \pm 1.2$ & $74.4 \pm 7.5$ \\
\hline $\mathrm{SiC}_{\mathrm{f}} / \mathrm{BNNTs} / \mathrm{BN}(20)-\mathrm{SiC}$ & 1.0 & $2.52 \pm 0.04$ & $6.92 \pm 1.6$ & $299.3 \pm 63.5$ & $14.0 \pm 1.1$ & $79.4 \pm 14.0$ \\
\hline $\mathrm{SiC}_{\mathrm{f}} / \mathrm{BNNTs} / \mathrm{BN}(40)-\mathrm{SiC}$ & 1.0 & $2.48 \pm 0.03$ & $8.27 \pm 1.8$ & $305.4 \pm 55.0$ & $12.2 \pm 0.3$ & $71.9 \pm 3.4$ \\
\hline
\end{tabular}

"Virgin $\mathrm{SiC}_{\mathrm{f}} / \mathrm{SiC}$ composites, as-grown, and $\mathrm{BN}$-coated $\mathrm{BNNTs}$ reinforced $\mathrm{SiC}_{\mathrm{f}} / \mathrm{SiC}$ hierarchical composites are denoted as $\mathrm{SiC}_{\mathrm{f}} / \mathrm{SiC}$.

The fracture surfaces of composites are inspected by SEM to figure out the effect of BNNTs/matrix interface tailoring on toughening in composites. As shown in Figs. 3(a) and 3(b), long fiber pull-outs are quite loose and each individual fiber can be distinguished, as shown clearly in virgin $\mathrm{SiC}_{\mathrm{f}} / \mathrm{SiC}$ composites. As as-grown BNNTs are introduced into the composites, short pull-outs of fibers stick to each other firmly and debonding cracks between fiber and matrix are sparsely observed intra fiber bundle as revealed in Figs. 3(c) and 3(d). So the morphology exhibits a fracture mode of fiber bundle pull-out. Although fiber bundle pull-outs also can dissipate some fracture energy as individual fiber pull-outs, toughening from each individual fibers is greatly undermined, which is detrimental to toughness of composites. It is commonly acknowledged that the interfacial bonding strength between fiber and matrix in composites is responsible for the individual fiber pull-out length and the whole morphology of fiber pull-outs. So the above result indicates that the interfacial bonding between fiber and matrix in as-grown BNNTs reinforced hierarchical $\mathrm{SiC}_{f} / \mathrm{SiC}$ composites is rather strong compared with that in virgin $\mathrm{SiC}_{\mathrm{f}} / \mathrm{SiC}$ composites. The enhancement of the interfacial bonding strength between fiber and matrix can be ascribed to BNNTs in situ grown on fiber surface. It is also in consistent with CNTs-based hierarchical composites, in which CNTs were employed to be grafted on fiber surface and consequently the interfacial bonding between fiber and matrix was reinforced effectively [10,13-17]. After the BNNTs/ matrix interface is optimized by the deposition of $\mathrm{BN}$ interphase, the fracture morphology of composites becomes similar with that of virgin $\mathrm{SiC}_{\mathrm{f}} / \mathrm{SiC}$ composites, as exhibited in Figs. 3(e) and 3(f). Although the pull-out lengths are still slightly shorter than that in virgin ones, fiber pull-outs in BN-coated BNNTs reinforced hierarchical $\mathrm{SiC}_{\mathrm{f}} / \mathrm{SiC}$ composites are much more obvious compared with that before interface tailoring. What is more, every individual fiber stands alone with each other and debonding cracks intra fiber bundle can be observed more easily, as confirmed in Fig. 3(f). It means that the interfacial bonding between fiber and matrix becomes weak after BNNTs/matrix interface tailoring.
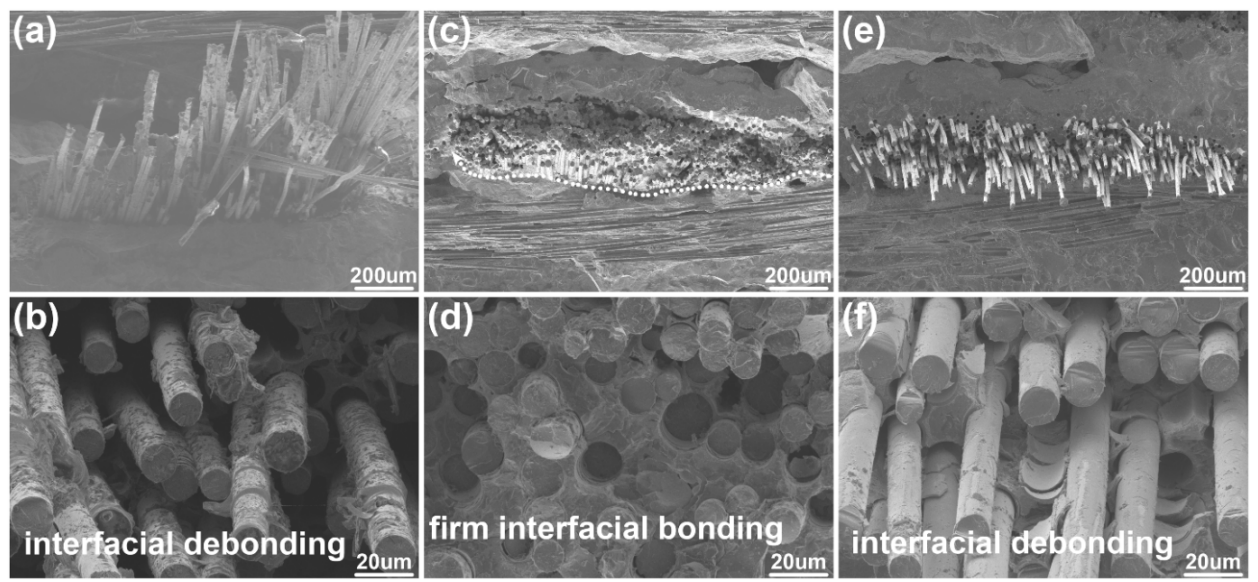

Fig. 3 Typical SEM images of fracture surfaces in (a) and (b) virgin $\mathrm{SiC}_{\mathrm{f}} / \mathrm{SiC}$ composites, (c) and (d) as-grown, (e) and (f) $\mathrm{BN}$-coated BNNTs reinforced $\mathrm{SiC}_{\mathrm{f}} / \mathrm{SiC}$ hierarchical composites. White dashed line portrays the crack path along the surface of fiber bundle. BN interphase was deposited for $20 \mathrm{~min}$. 
The interfacial shear strength (IFSS) between fiber and matrix is characterized quantitatively by single fiber push-out test to further verify the above analysis. Representative indentation load vs. displacement curves and SEM images of pushed fibers are depicted in Fig. 4. The IFSS values are also listed in Table 1, which can be calculated using the equation in the experimental section. It can be seen clearly from Fig. 4(a) that fibers in virgin $\mathrm{SiC}_{\mathrm{f}} / \mathrm{SiC}$ composites can be pushed out easily under a relative low load and fiber/matrix interface is basically intact. The corresponding IFSS is $59.4 \pm 12.0$ $\mathrm{MPa}$. When BNNTs are in situ grown on fiber surface, it becomes difficult to push out the fibers unless a rather high load is applied and brittle fracture occurs at fiber/matrix interface, as exhibited in Fig. 4(b). The IFSS calculated according to the high push-out load is 119.6 $\pm 11.4 \mathrm{MPa}$, showing a significant increase. It demonstrates that the interfacial bonding strength between fiber and matrix are greatly improved by in situ growing BNNTs on fiber surface.

The push-out load decreases and brittle fracture at fiber/matrix interface disappears in some degree after BN interphase is deposited on nanotube surface, as shown in Fig. 4(c). The IFSS values decrease to $74.4 \pm 7.5,79.4 \pm 14.0$, and $71.9 \pm 3.4 \mathrm{MPa}$ with deposition time of 10, 20, and $40 \mathrm{~min}$ respectively, which are still higher than that in virgin $\mathrm{SiC}_{\mathrm{f}} / \mathrm{SiC}$ composites. This result can exactly account for the small distinction in the fiber pull-out length between these two composites, as described in Figs. 3(a) and 3(e). So it can be concluded that the improvement of the interfacial bonding strength between fiber and matrix can be alleviated dramatically when BNNTs/matrix interface is optimized via depositing BN interphase on nanotube surface. The result from fiber push-out test is perfectly in accordance with the above analysis about fracture morphologies of composites.
Apart from micro-scale fiber reinforcements, nanotubes can serve as the secondary reinforcements in nanotube-based hierarchical composites by energy dissipation mechanisms at nanoscale. The effect of $\mathrm{BNNTs} /$ matrix interface tailoring on the fracture morphology of micro-scale fibers has been discussed above elaborately. It is also necessary to scrutinize the influence of BNNTs/matrix interface tailoring on the toughening effect of BNNTs. After all, BNNTs/matrix interfacial bonding dictates the feature of pull-outs of BNNTs directly and thus affects the toughening effect of BNNTs. Interphase is an important factor that influences the properties of ceramic matrix composites. As long as $\mathrm{BN}$ interphase is applied to optimize the bonding condition between BNNTs and matrix, BN interphase can liberate the enhancement of BNNTs and many pull-outs can be found. Figure 5 illustrates the fracture morphologies of as-grown and BN-coated BNNTs in matrix. Few or short pull-outs of BNNTs can be observed in as-grown BNNTs reinforced hierarchical $\mathrm{SiC}_{\mathrm{f}} / \mathrm{SiC}$ composites, as shown by white circles in Figs. 5(a) and 5(b). BNNTs tend to break off with a brittle fracture mode and thus be left in matrix, as revealed by white arrows in Fig. 5(a). It indicates that the BNNTs/matrix interfacial bonding is too strong for the pull-out of nanotubes. This phenomenon is also discovered in our previous study [6].

Two reasons are responsible for this phenomenon. On one hand, BNNTs have the unique morphology of the bubble-chain tube walls, as displayed in Fig. 1(b). Obvious periodical knots can be seen from Fig. 1(b). These knots can act as structural anchors and result in mechanical interlocking between the matrix and BNNTs, and thus enhance the interface bonding. It also agrees with the reported results about other nanotubes or nanowires with similar morphology [18-21]. On the other hand, the interface bonding is also strengthened
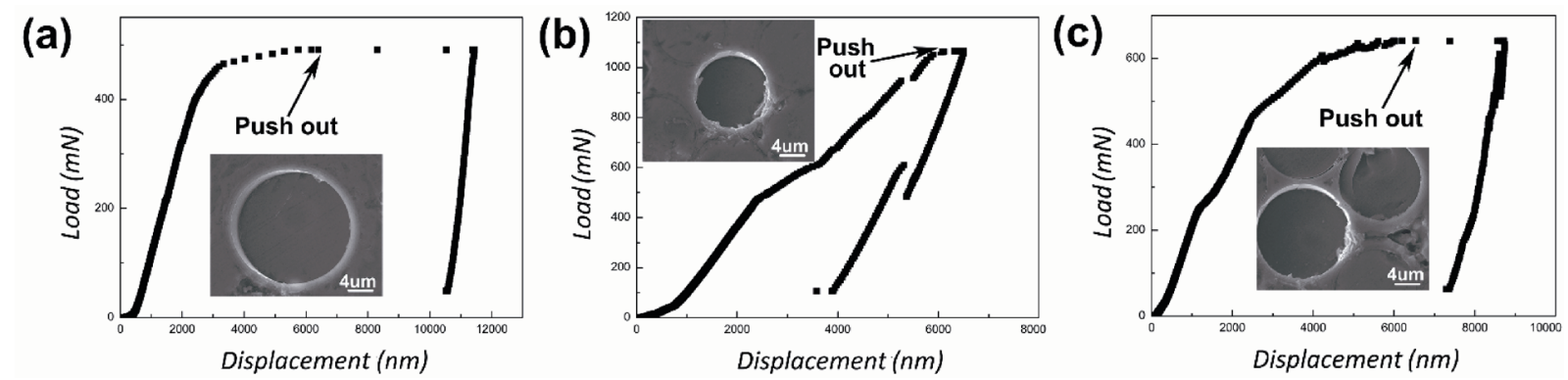

Fig. 4 Representative indentation load vs. displacement curves along with SEM images of pushed fibers of (a) virgin $\mathrm{SiC}_{\mathrm{f}} / \mathrm{SiC}$ composites, (b) as-grown, and (c) BN-coated BNNTs reinforced $\mathrm{SiC}_{\mathrm{f}} / \mathrm{SiC}$ hierarchical composites under single fiber push-out test. BN interphase was deposited for $20 \mathrm{~min}$. 

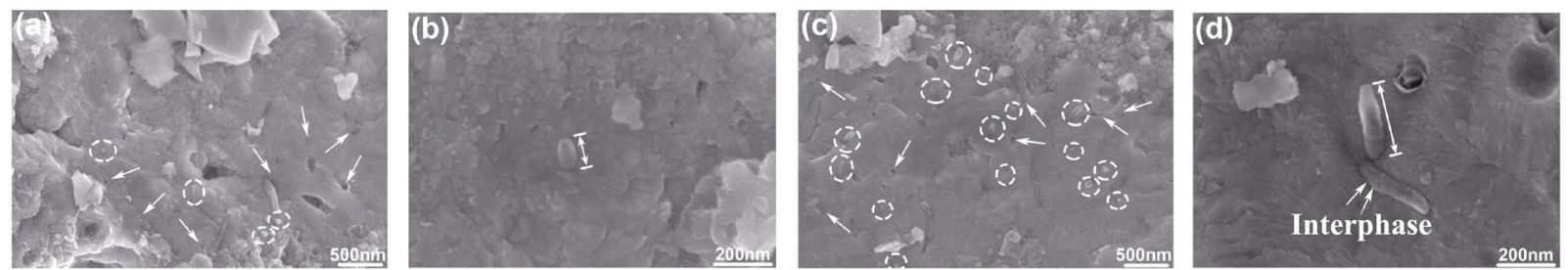

Fig. 5 Typical SEM images of fracture morphologies of (a) and (b) as-grown, (c) and (d) BN-coated BNNTs in matrix. BN interphase was deposited for $20 \mathrm{~min}$. White arrows and circles in the upside images indicate the broken nanotubes left in matrix with brittle fracture mode and the pull-outs of nanotubes, respectively.

by the thermal residual clamping stress exerted on the interface [22-24]. When the composites are cooled from the final densification temperature to room temperature, $\mathrm{SiC}$ matrix shrinks faster than BNNTs because the coefficient of thermal expansion (CTE) of BNNTs is lower than that of matrix [24,25]. It can lead to the radial clamping stress on the interphase. Consequently, BNNTs/matrix interfacial bonding is enhanced. As a result of the strong mechanical interlocking and clamping stress, cracks are difficult to be deflected at the BNNTs/matrix interface and pull-outs of BNNTs are hindered. In this case, less fracture energy can be dissipated and the toughening effect of nanotubes is limited.

On the contrary, BNNTs prefer to be pulled out when a layer of $\mathrm{BN}$ interphase is deposited on nanotube surface, as exhibited in Fig. 5(c). What is more, it can be seen from Fig. 5(d) that the pull-out lengths of nanotubes with $\mathrm{BN}$ interphase are longer than the ones without BN interphase. So it can be concluded that the $\mathrm{BNNTs} /$ matrix interfacial bonding strength is reduced after the deposition of $\mathrm{BN}$ interphase on the nanotube surface. The thickness of $\mathrm{BN}$ interphase can be narrowed to $40-45 \mathrm{~nm}$ through TEM picture in Fig. 2(b) and the interphase can act as a buffer and relieve the residual clamping stress caused by CTE mismatch. Besides, interlocking effect resulting from obvious knots also greatly fades due to the disappearance of bubble-chain morphology, as indicated in Fig. 1. In this case, BNNTs/matrix interface debondings are allowed. These debondings can activate nanotube toughening mechanisms such as crack deflection, nanotube bridging, sliding, and pull-out. More fracture energy can be dissipated during the process and toughening of local matrix among fibers is realized.

In-depth investigation on the crack deflection mode at the BNNTs/matrix interface can be found in Fig. 6(a). It can be inspected clearly that the interphase adheres to both the BNNT surface and the matrix, as pointed out by white arrows. It is also confirmed by the
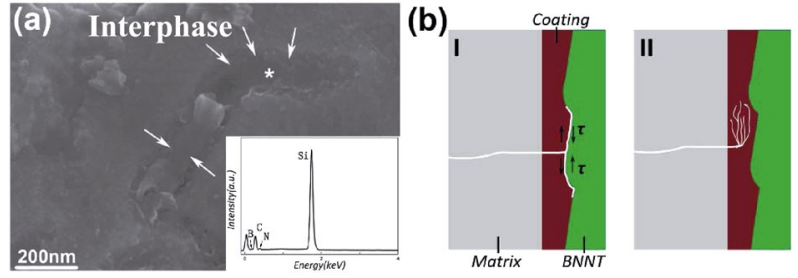

Fig. 6 (a) High-magnification SEM image of debonding morphology at the BNNTs/matrix interface. White arrows indicate the adherence of the interphase. The inset shows EDS result taken from the debonding zone as marked by white asterisk in the image. (b) Schematic diagrams depicting crack deflection at the BNNTs/matrix interface.

EDS result taken from the debonding zone in matrix as marked by white asterisk, in which $\mathrm{B}$ and $\mathrm{N}$ peaks are presented. Figure 5(b) also shows the adherence of the interphase to the BNNT surface. So it is believed that debonding cracks at the BNNTs/matrix interface zone are deflected within the interphase. In conventional fiber reinforced composites, the interphase prefers to be designed as mode II instead of mode I [8,26,27], as depicted in Fig. 6(b). Under this circumstance, crack deflection occurs in a diffuse manner within the interphase. The turbostratic structure of BN interphase can deflect the cracks along atomic planes into short and branched multiple cracks [27]. Consequently, energy dissipation is increased by such branched multiple cracks and good fiber sliding friction within the interphase. For BNNTs in this paper, this preferred mode is obtained at nanoscale, as verified in Fig. 6(a) and schematically presented in Fig. 6(b). It is beneficial for BNNTs to give full scope to toughening in matrix.

\section{Discussions}

Based on the results described above, corresponding toughening mechanisms of BNNTs/matrix interface tailoring are analyzed as follows. In hierarchical composites, fibers and BNNTs produce energy dissipation 
mechanisms to toughen the composites at micro-scale and nanoscale level, respectively. Not only does BNNTs/matrix interface tailoring affect the toughening effect of BNNTs but also changes that of fibers. Without an interphase, crack deflection by BNNTs and pull-outs of BNNTs are hindered due to strong BNNTs/ matrix interfacial bonding. It limits the toughening effect of nanotubes. With the deposition of BN interphase, $\mathrm{BNNTs}$ /matrix interface debondings are allowed and toughening from BNNTs can be realized. BNNTs/matrix interface tailoring can influence fiber/matrix interfacial bonding and thus change the toughening effect of fibers. It is believed that as-grown BNNTs without an interphase, extending into the matrix, can cause strong mechanical interlocking between fibers and matrix and help fibers anchored into matrix via a manner similar with what roots can do to a tree $[28,29]$. This anchorage is quite strong especially when BNNTs/matrix interfacial bonding is sufficiently tight. In this case, fiber/matrix debondings and fiber pull-outs are impeded in large part. It inhibits the toughening from fibers. However, after tailoring BNNTs/matrix interface by the deposition of BN interphase, the anchorage effect to fibers can be largely abated because BNNTs/matrix interfacial bonding strength decreases. As a result, fiber/matrix interfacial bonding strength declines. Fiber pull-outs become easy again. So it can be concluded that without BNNTs/matrix interface tailoring toughening effects of fibers and BNNTs both fail substantially. This phenomenon induces relatively low fracture toughness of hierarchical composites, as found in Table 1. The deposition of $B N$ interphase can eliminate the malfunction of toughening effects of fibers and BNNTs. Thus, fracture toughness of hierarchical composites can be improved, as verified in Table 1. From perspective of crack propagation, the effect of BNNTs/matrix interface tailoring also can be well explained, as schematically illustrated in Fig. 7. In virgin $\mathrm{SiC}_{\mathrm{f}} / \mathrm{SiC}$ composites, cracks propagate easily without being hindered in matrix. When arriving at fiber/matrix interface, cracks are deflected along the fibers. Interface debondings occur and fibers can be pulled out, as depicted in Fig. 7(a). When BNNTs are in situ grown on fiber surface, BNNT network can inhibit crack propagations towards fiber/matrix interface or along the fiber axial direction [30]. It means that fiber/matrix interfacial bonding is enhanced. Moreover, because of strong BNNTs/matrix interfacial bonding cracks cannot be deflected and fail to bypass BNNTs.

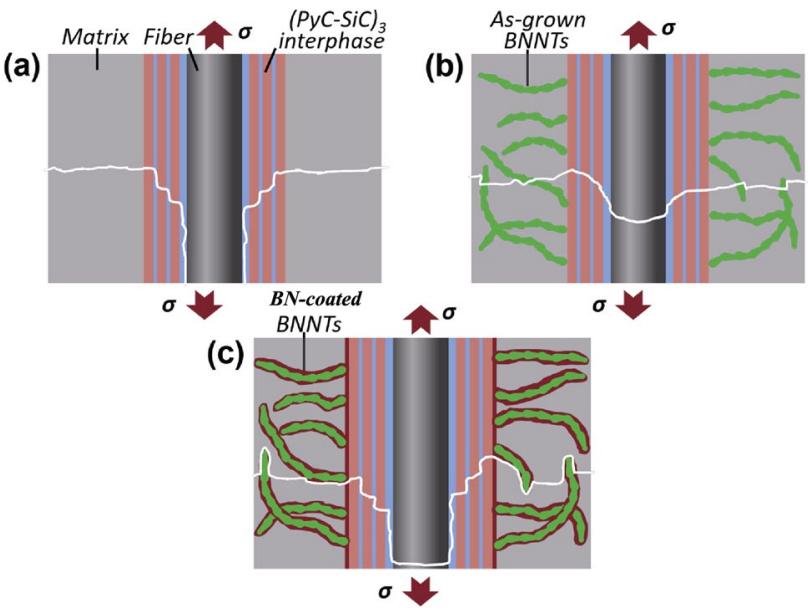

Fig. 7 Schematic presentation of crack propagations in (a) virgin $\mathrm{SiC}_{\mathrm{f}} / \mathrm{SiC}$ composites, (b) as-grown, and (c) BN-coated BNNTs reinforced $\mathrm{SiC}_{\mathrm{f}} / \mathrm{SiC}$ hierarchical composites.

As bending stress of the composite increases, the stress at the crack tip accumulates gradually and BNNTs will break finally instead of being pulled out. After the break of BNNTs, cracks can get to fiber/matrix interface. But bending stress of the composite at this time is in relatively high level. It will cause the instant break of fibers rather than interface debonding, as presented in Fig. 7(b). Besides, BNNT network intra fiber bundle also limits crack propagations into fiber bundle. It can result in few debonding cracks in the fiber bundle [17], as shown in Fig. 3(d). Cracks tend to propagate along the surface of fiber bundle where hindering effect from BNNTs is weak enough, as indicated by white dashed line in Fig. 3(c). On the contrary, after the deposition of the interphase, crack deflections happen at the BNNTs/matrix interface and cracks can bypass BNNTs easily by BNNTs/matrix interface debondings, as illustrated in Fig. 7(c). Stress concentration at the crack tip is relaxed. Fibers/matrix interfacial bonding strength decreases and fiber/matrix interface debondings and fiber pull-outs are allowed. Consequently, toughening effects of both fibers and BNNTs are well gained.

\section{Conclusions}

$\mathrm{BN}$-coated BNNTs reinforced hierarchical $\mathrm{SiC}_{\mathrm{f}} / \mathrm{SiC}$ composites are fabricated to investigate the effect of $\mathrm{BNNTs} /$ matrix interface tailoring in this research. BN interphase on BNNT surface is applied by CVD method. Due to strong BNNTs/matrix interfacial 
bonding, toughening effect of as-grown BNNTs is undermined and crack propagations towards fiber/matrix interface and into fiber bundle are hindered. The fiber/matrix interfacial bonding is enhanced greatly by the strong anchorage effect from as-grown BNNTs. Consequently, toughening effect of fibers is also undermined. After the deposition of $\mathrm{BN}$ interphase, BNNTs/matrix and fiber/matrix interfacial bonding can be optimized. This optimization can activate energy dissipation mechanisms at nanoscale and micro-scale level induced by BNNTs and fibers, respectively. As a result, fracture toughness of hierarchical $\mathrm{SiC}_{\mathrm{f}} / \mathrm{SiC}$ composites can be improved evidently.

\section{Acknowledgements}

This work is supported by National Natural Science Foundation of China (Grant Nos. 51772310 and 51502323), the National Key Research and Development Program of China (Grant No. 2017YFB0703200), the research grant from Science and Technology Commission of Shanghai Municipality (Grant No. 16DZ2260600), Science Foundation for Youth Scholar of State Key Laboratory of High Performance Ceramics (Grant No. SKL201601), and Chinese Academy of Science (Grant No. QYZDY-SSW-JSC031).

\section{References}

[1] Lee C, Bhandari S, Tiwari B, et al. Boron nitride nanotubes: Recent advances in their synthesis, functionalization, and applications. Molecules 2016, 21: 922.

[2] Wang YJ, Chen H, Li YJ. Review on the application of boron nitride nanotubes. In: Proceedings of the 2016 5th International Conference on Environment, Materials, Chemistry and Power Electronics, 2016.

[3] Pakdel A, Zhi CY, Bando Y, et al. Low-dimensional boron nitride nanomaterials. Mater Today 2012, 15: 256-265.

[4] Lahiri D, Agarwal A. Boron nitride nanotubes as nanofillers/reinforcement for polymer, ceramic, and metal matrix composites. In: Nanotubes and Nanosheets. Chen Y, Ed. CRC Press, 2015: 495-524.

[5] Tatarko P, Grasso S, Porwal H, et al. Boron nitride nanotubes as a reinforcement for brittle matrices. $J$ Eur Ceram Soc 2014, 34: 3339-3349.

[6] Zhu GX, Dong SM, Ni DW, et al. Microstructure, mechanical properties and oxidation resistance of $\mathrm{SiC}_{\mathrm{f}} / \mathrm{SiC}$ composites incorporated with boron nitride nanotubes. $R S C$ Adv 2016, 6: 83482-83492.

[7] Yang YC, Liang X, Chen WB, et al. Quantification and promotion of interfacial interactions between carbon nanotubes and polymer derived ceramics. Carbon 2015, 95 : 964-971.

[8] Naslain RR. The design of the fibre-matrix interfacial zone in ceramic matrix composites. Compos Part A: Appl Sci Manuf 1998, 29: 1145-1155.

[9] Wang HD, Zhou HJ, Dong SM, et al. Corrosion behavior of $\mathrm{SiC}_{\mathrm{f}} / \mathrm{SiC}$ composites in high temperature fluoride salt environment. J Inorg Mater 2017, 32: 1133-1140.

[10] Zhu GX, Dong SM, Hu JB, et al. In situ growth behavior of boron nitride nanotubes on the surface of silicon carbide fibers as hierarchical reinforcements. $R S C A d v$ 2016, 6: 14112-14119.

[11] Hinoki T, Zhang W, Kohyama A, et al. Effect of fiber coating on interfacial shear strength of $\mathrm{SiC} / \mathrm{SiC}$ by nano-indentation technique. J Nucl Mater 1998, 258-263: 1567-1571.

[12] Dugne O, Prouhet S, Guette A, et al. Interface characterization by TEM, AES and SIMS in tough SiC (ex-PCS) fibre-SiC (CVI) matrix composites with a BN interphase. J Mater Sci 1993, 28: 3409-3422.

[13] Godara A, Gorbatikh L, Kalinka G, et al. Interfacial shear strength of a glass fiber/epoxy bonding in composites modified with carbon nanotubes. Compos Sci Technol 2010, 70: $1346-1352$.

[14] Lachman N, Wiesel E, de Villoria RG, et al. Interfacial load transfer in carbon nanotube/ceramic microfiber hybrid polymer composites. Compos Sci Technol 2012, 72: 1416-1422.

[15] Qian H, Bismarck A, Greenhalgh ES, et al. Hierarchical composites reinforced with carbon nanotube grafted fibers: The potential assessed at the single fiber level. Chem Mater 2008, 20: 1862-1869.

[16] Zhang FH, Wang RG, He XD, et al. Interfacial shearing strength and reinforcing mechanisms of an epoxy composite reinforced using a carbon nanotube/carbon fiber hybrid. $J$ Mater Sci 2009, 44: 3574-3577.

[17] Hu JB, Dong SM, Zhang XY, et al. Process and mechanical properties of carbon/carbon-silicon carbide composite reinforced with carbon nanotubes grown in situ. Compos Part A: Appl Sci Manuf 2013, 48: 73-81.

[18] Olek M, Ostrander J, Jurga S, et al. Layer-by-layer assembled composites from multiwall carbon nanotubes with different morphologies. Nano Lett 2004, 4: 1889-1895.

[19] Dong RH, Yang WS, Wu P, et al. Effect of reinforcement shape on the stress-strain behavior of aluminum reinforced with SiC nanowire. Mater Des 2015, 88: 1015-1020.

[20] Chu YH, Li HJ, Wang YJ, et al. Microstructure and mechanical properties of ultrafine bamboo-shaped $\mathrm{SiC}$ rod-reinforced HfC ceramic coating. Surf Coat Technol 2013, 235: 577-581.

[21] Tao XY, Liu J, Koley G, et al. $\mathrm{B} / \mathrm{SiO}_{x}$ nanonecklace reinforced nanocomposites by unique mechanical interlocking mechanism. Adv Mater 2008, 20: 4091-4096.

[22] Kim JK, Zhou LM, Mai YW. Interfacial debonding and fibre pull-out stresses, Part III Interfacial properties of cement matrix composites. J Mater Sci 1993, 28: 3923-3930.

[23] Kalton AF, Howard SJ, Janczak-Rusch J, et al. Measurement 
of interfacial fracture energy by single fibre push-out testing and its application to the titanium-silicon carbide system. Acta Mater 1998, 46: 3175-3189.

[24] Nisar A, Ariharan S, Balani K. Synergistic reinforcement of carbon nanotubes and silicon carbide for toughening tantalum carbide based ultrahigh temperature ceramic. $J$ Mater Res 2016, 31: 682-692.

[25] Mashreghi A. Thermal expansion/contraction of boron nitride nanotubes in axial, radial and circumferential directions. Comput Mater Sci 2012, 65: 356-364.

[26] Naslain R. Design, preparation and properties of non-oxide CMCs for application in engines and nuclear reactors: An overview. Compos Sci Technol 2004, 64: 155-170.

[27] Rebillat F, Lamon J, Guette A. The concept of a strong interface applied to $\mathrm{SiC} / \mathrm{SiC}$ composites with a $\mathrm{BN}$ interphase. Acta Mater 2000, 48: 4609-4618.

[28] $\mathrm{Hu} \mathrm{JB}$, Dong $\mathrm{SM}, \mathrm{Wu} \mathrm{B}$, et al. Tailoring carbon fiber/carbon nanotubes interface to optimize mechanical properties of $\mathrm{C}_{\mathrm{f}}$-CNTs/SiC composites. Int J Appl Ceram Technol 2014, 11: 207-217.

[29] Hung KH, Kuo WS, Ko TH, et al. Processing and tensile characterization of composites composed of carbon nanotube-grown carbon fibers. Compos Part A: Appl Sci Manuf 2009, 40: 1299-1304.

[30] Song Q, Li KZ, Li HL, et al. Grafting straight carbon nanotubes radially onto carbon fibers and their effect on the mechanical properties of carbon/carbon composites. Carbon 2012, 50: 3949-3952.

Open Access This article is licensed under a Creative Commons Attribution 4.0 International License, which permits use, sharing, adaptation, distribution and reproduction in any medium or format, as long as you give appropriate credit to the original author(s) and the source, provide a link to the Creative Commons licence, and indicate if changes were made.

The images or other third party material in this article are included in the article's Creative Commons licence, unless indicated otherwise in a credit line to the material. If material is not included in the article's Creative Commons licence and your intended use is not permitted by statutory regulation or exceeds the permitted use, you will need to obtain permission directly from the copyright holder.

To view a copy of this licence, visit http://creativecommons.org/licenses/by/4.0/. 